\title{
Technology Mediated Learning: Observations in Two Technologies
}

\author{
Raafat George Saadé, Meral Demirbağ Büyúkkurt, \\ and Cynthia Alkhori \\ Department of Decision Sciences and MIS, \\ John Molson School of Business, Concordia University, \\ Montreal, Quebec, Canada
}

\section{rsaade@jmsb.concordia.ca; mbuyukkurt@jmsb.concordia.ca; cynthia.alkhori@gmail.com}

\begin{abstract}
The study presented in this paper explores three critical dimensions of technology-mediated learning. Identifying the dimensions entails important issues which are of great relevance to the way educators teach OR/MIS courses today. The primary question is "how do important factors contribute to the success/failure of two variations of technology-mediated learning?" In order to answer this question, constructs that measure students' perceptions are identified and measured in order to understand the learning experience of students using the different technologies. In this study, we explored technology mediated learning dimensions of students' attitudes, affects, and motivations. Data was collected from students in two classes where one used a web-based learning tool, while the other used clickers and peer instruction. 105 and 174 students completed the questionnaire for the web-based tool and clicker and peer instruction, respectively. An exploratory factor analysis was used and items relevant to the two different contexts were identified. Constructs' properties were found to be different between the two contexts.
\end{abstract}

Keywords: Clickers, Peer Instruction, Affect, Beliefs, Motivation, Learning, Attitudes

\section{Introduction}

Education today has completed a full cycle, expanding from the traditional in-class environment to the new digital e-learning where teaching is completely online, and back to the classroom where teaching is assisted by technology. E-learning tools are any web sites, software, or computer-assisted activities that intentionally focus on and facilitate learning on the Internet (Poole \& Lorrie, 2003; Saadé et al., 2010). Learning tools that have been investigated by researchers include web based dynamic practice systems, multimedia applications and game based learning

Material published as part of this publication, either on-line or in print, is copyrighted by the Informing Science Institute. Permission to make digital or paper copy of part or all of these works for personal or classroom use is granted without fee provided that the copies are not made or distributed for profit or commercial advantage AND that copies 1) bear this notice in full and 2) give the full citation on the first page. It is permissible to abstract these works so long as credit is given. To copy in all other cases or to republish or to post on a server or to redistribute to lists requires specific permission and payment of a fee. Contact Publisher@InformingScience.org to request redistribution permission. modules (Saadé, 2003; Sunal et al., 2003). These learning tools focus on specific learning aspects and try to meet the learning needs of a particular group of learners.

While internet based learning continue to reach new heights, the technology mediated classroom is beginning to take off. Many instructors have been using a classroom technology that allows students to respond and interact via small 
hand-held devices called "Clickers". Clickers allow instructors to collect and tally student's responses to questions and display the summary of the results on a projector screen. They create a classroom environment that fosters learning not only by engaging students in answering questions but also by providing instant feedback to them. Additionally, students are encouraged to discuss their responses with a small group of their peers before finalizing them. The benefits of this peer instruction have been thoroughly investigated by the Mazur Group at Harvard University (Lasry et al., 2008).

A review of previous literature led us to identify three theories that have been used to evaluate experiences of those using technology that are relevant to this research. These theories are: theory of reasoned action (TRA), theory of planned behavior (TPB), and the motivational model (MM). Four recurring and important constructs were selected from these theories as the dimensions of technology mediated learning of interest: affect, attitude, intrinsic motivation and extrinsic motivation. Items (questions) for these variables from different studies were incorporated into a survey designed for data collection. Exploratory factor analysis was used to compare the resulting constructs obtained from the clicker and peer instruction class and the online class.

\section{Theoretical Background}

\section{Technology-mediated Learning}

Technology-mediated learning includes both e-learning (which is viewed as courses delivered totally on the Web) and computer-assisted learning using any technology such as clickers. Alavi \& Leidner (2001) define technology-mediated learning as "an environment in which the learner's interactions with learning materials, peers, and/or instructor are mediated through advanced information technology". There are many factors that influence online learning and these factors might have direct or indirect relationships with each other. Gupta \& Bostrom (2009) developed a technology mediated learning framework based on: learning structures, relationship among these structures, the social system where the learning environment is taking place, appropriation of the structures, influence on social context or reciprocal causation, and influence of actors and power dynamics.

Although their technology mediated learning framework does not explicitly address learning theories, it actually allows for the implementation of various pedagogies most appropriate to the context of the learning environment. One learning theory that seems to be most appropriate to apply to the framework is constructivism. The constructivist approach to learning is now widely accepted in the educational community (Dalgarno, 2001; Saadé \& Huang, 2009). Constructivism is viewed today as the construction of knowledge occurring in the mind of the individual and within his/her perception of the world. The process of learning involves the linking/thinking of newly acquired knowledge with old internalized knowledge. Technology has contributed to the constructivist theory by providing a wide range of technology mediated learning resources such as simulations, microworlds, intelligent agents, adaptive systems, cognitive tools, and practice tools. The constructivist approach can be implemented into the technology mediated learning framework via the definition of the constructive elements of the learning structures, the social system where learning is taking place and the power dynamics among the actors to create an environment where knowledge is allowed to be created in the minds of the students via the use of a technology.

A technology mediated instructional system for learning is not simply created by including interactivity and multimedia. There is a strong urge to include the "learning" component into the design. As early as 1989, Mayer (1989) had proposed a learning process model that provides a theoretical framework for incorporating "learning" knowledge into a web-based instructional system. 
Mayer's (1989) original learning process model entailed the summation of materials to be learned, presentation method and learner's characteristics affecting the learning process which leads to learning outcomes and in turn leads to learning performance. A feedback loop is identified from the learning outcome to the learner characteristics. Guided by the generalized framework for technology-mediated learning by Gupta \& Bostrom (2009), the work by Mayer (1989), and recent research related to the acceptance of technology for learning, we identify affect, attitude and motivation as critical dimension to technology mediated learning and which are elaborated in the following section.

\section{Beliefs and Emotions}

Although the body of literature on beliefs and emotions is large and growing, its subset dealing with students' beliefs towards technology mediated learning is small (Saadé, 2007; Saadé and Bahli, 2005; Valenta et al., 2001). The theory of planned behavior (TPB) (Ajzen, 1985) is useful in explaining beliefs towards technology mediated classrooms. The historical antecedent of the TPB lies in the theory of reasoned action (TRA) (Fishbein \& Azjen, 1975).

The TRA identifies the proximal determinants of behavior as the strength of an intention to whether or not engage in that behavior. In turn, antecedents to behavioral intentions were identified from two cognitive processes namely attitudes and behavioral norms. Attitudes towards a behavior can be measured from beliefs about the behavior under consideration and valences attached to those beliefs. Behavioral norms include the influence of parents and friends, whose opinions are important to the individual, to engage or not in the behavior under consideration and the individuals' motivation to comply (Bozionelos \& Bennett, 1999). Intentions accurately predict behavior only when the behavior is under the individuals' volitional control (Fishbein \& Ajzen, 1975). To account for such factors, a third variable, perceived behavioral control, was incorporated into the theory of reasoned action resulting in the theory of planned behavior.

It is clear that beliefs and associated evaluations lead to intentions. With respect to the use of technology for learning, attitudes of an individual might be his/her belief that by using the technology, the individual can successfully complete the course requirements thereby improving performance (Saadé, 2007).

Based on the above, two belief constructs and two motivational constructs that have been consistently significant in information systems research are identified. These constructs have been used extensively in information systems research to understand students' behavior, satisfaction and adoption of information systems. However, to the best of our knowledge there has not been any use of these models and constructs in the context of technology mediated classroom. In the next section, we elaborate on the constructs chosen for this study.

\section{Clickers}

While considerable literature on clickers is anecdotal coverage of how clickers were used and what the students' reactions were, recently there are reports of empirical research on clicker use (Campbell \& Mayer, 2009; Mayer et al., 2009; Patterson et al, 2010; Sprague \& Dahl, 2009). Students' perceptions of learning engagement (Mayer et al., 2009; Patterson et al, 2010; Stagg \& Lane, 2010), satisfaction with clickers (Sprague \& Dahl, 2009), perceptions of fun (Patterson et al, 2010) were among the variables of interest relevant to the current research.

\section{Dimensions to Technology-Mediated Learning}

A recent study, Sunal et al. (2003) analyzed a body of research on best practices in asynchronous or synchronous online instruction in higher education. The study indicated that online learning is viable and resulted in the identification of potential best practices. Most studies on student behav- 
ior were found to be anecdotal and thus not evidence based. Researchers today are concerned with exploring student behavior and attitudes towards online learning but only a few have started to report on experiences with technology use in the classroom. The evaluation of students' motivations and attitudes in a classroom that uses technology as part of its instructional method is scarce. Motivated by the need for more research in this area, we identified four factors/dimensions that may be used to better understand student motivation and attitude towards technology-mediated learning. These factors which we shall refer to as the dimensions to a computer mediated classroom are affect, attitudes, intrinsic motivation and extrinsic motivation.

Affect: Affect refers to an individual's feelings of joy, elation, pleasure, depression, distaste, discontentment, or hatred with respect to particular behavior (Triandis, 1980). Triandis (1980) argued that literature showed a strong relationship between affect and behavior. Positive affect towards technology leads to gaining experience, knowledge and self-efficacy regarding technology, and negative affect causes avoiding technology, thereby not learning about them or developing perceived control (Arkkelin, 2003).

Attitude: Attitude has been identified as an essential intention determinant to behavioral intention, as described by the well-established theory of reasoned action. Most of the online learning literature concentrates on students' and instructors' attitudes towards online learning (Saadé et al., 2010; Sunal et al., 2003). Marzano and Pickering (1997) indicated that students' attitude will impact the level of learning they achieve. Also research has been conducted to validate this assertion and extends this assertion into an on-line environment (Daley et al, 2001; Saadé, 2007; Saadé and Galloway, 2005; Saadé et al., 2009).

Intrinsic Motivation: Researchers have also studied motivational perspectives to understand behavior. Davis et al. (1992) have advanced this motivational perspective to understand behavioral intention concerning technology to predict the acceptance of technology. They found intrinsic and extrinsic motivation to be key drivers of behavioral intention to use technology (Venkatesh, 1999; Vallerand, 1997). Wlodkowski (1999) defines intrinsic motivation as an evocation, an energy called forth by circumstances that connect with what is culturally significant to the person. Intrinsic motivation is grounded in learning theories and is now being used as a construct to measure user perceptions of game/multimedia technologies (Venkatesh, 1999; Venkatesh \& Davis, 2000; Venkatesh et al., 2002).

Extrinsic Motivation: Extrinsic motivation was defined by Deci and Ryan (1985) as the performing of a behavior to achieve a specific reward. In students' perspective, extrinsic motivation on learning may include getting higher grades in exams, getting awards, etc. A lot of research has already verified that extrinsic motivation is an important factor influencing learning. However, other research also addresses that extrinsic motivation is not as effective as intrinsic motivation in motivating learning or using technology to facilitate learning (Saadé, 2007).

\section{Methodology}

Exploratory factor analysis (EFA) was conducted separately with data from each of the two technology-mediated classes. Since factor analysis simplifies the structure of the data by grouping together observed variables that are inter-correlated under one "common" factor (or in the context of this study, dimension), our intension was to compare the resulting factor structures. The two technology-mediated classes were one that used clickers and peer instruction and the other that was an online course (Saadé et al., 2007). In this paper we include only a brief description of the online study (please refer to Saadé et al., 2007 for more details) and will elaborate mostly on the comparison of the two contexts. Prior to the presentation of the EFA approach and results, we describe the tool used, the experimental setup including participants and procedure and the questionnaire used. 


\section{The Technologies Used}

\section{Online course}

The web-based tool in the online course was developed so that the students could practice and assess their knowledge of concepts to be learned in an introductory management information systems course. The learning tool helped students rehearse as well as learn by prompting them with multiple choice, and true or false questions. Since it could be accessed using any web browser, students were allowed to use the system anywhere, anytime.

\section{Clicker and peer instructions}

The process of using clickers and peer instruction is shown in Figure 1. The professor in each lecture first covered a series of concepts, and then displayed a multiple choice question about a challenging aspect of the concepts. The students were encouraged to discuss their answers to the question with 2-3 peers sitting next to them. When they were convinced of the correctness of their answers, students "clicked" their answers. After 1-2 minutes of peer instruction, the professor turned off voting and displayed the number of selections of each choice in a bar chart and identified the correct answer. The professor then gave further clarifications and answered questions before moving to another concept.

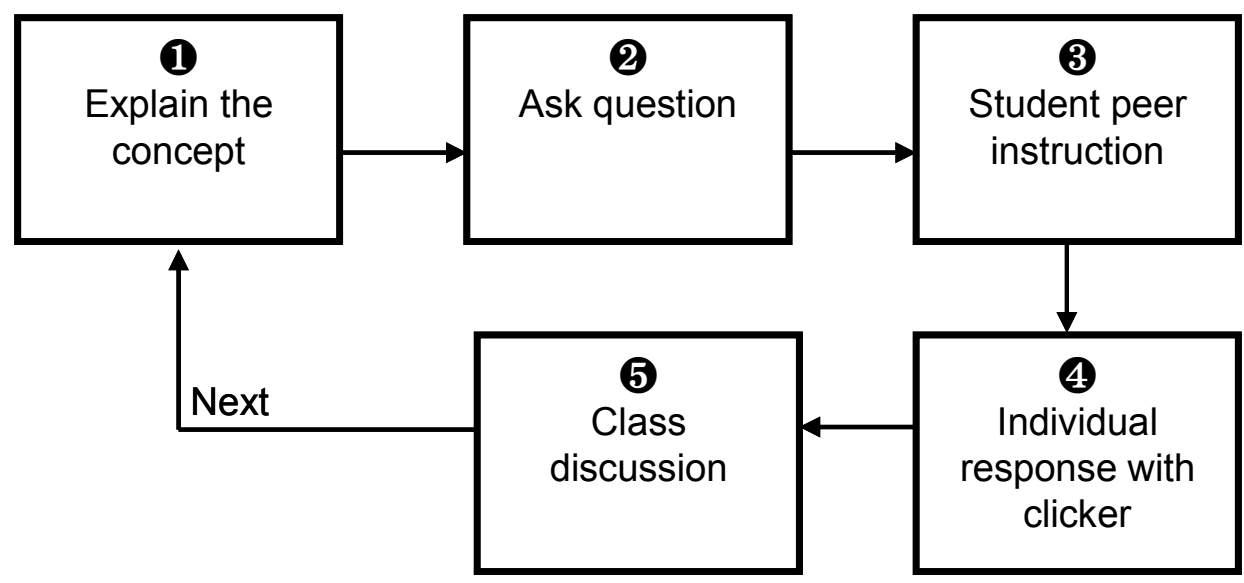

Figure 1: Procedure for clickers and peer instruction.

\section{Participants and Procedure}

\section{Online course}

A total of 105 undergraduate students in a business school in Canada participated in using the online learning tool. First, the students were asked to study a chapter prior to the use of the online learning tool. Once the student studied the chapter, he/she could practice answering the questions associated with the chapter. The practice component prompted the student with a set of five questions at a time. The student answered the questions and requested to be evaluated. The online learning tool then distinguished the correct from the incorrect answers. The student could verify the results and when ready request another set of 5 questions randomly selected from a pool of questions. The student could practice as much as $\mathrm{s} / \mathrm{he}$ felt was necessary before $\mathrm{s} / \mathrm{he}$ did the test for that chapter. The student could then continue with another cycle identified by a new chapter to study and practice. The system would monitor and store students' activities such as usage time, chapters being accessed and average scores per chapter and time stamp them. When a student felt ready for the test, s/he was directed to a site similar to the practice one where they were able to 
take the test online. Both, practice and final test had the same interface, engine and pool of questions.

\section{Clickers and peer instruction}

A total of 266 students in three sections of a business statistics course were taught by the same professor using clickers. Students were introduced to clickers in the course outline, in a PowerPoint file created by i-clicker Company, and during the first class of the semester. In order to facilitate students' preparation for each class, they were required to answer questions about how they prepared for that week's class ad answer a few multiple choice questions about the chapter content. During the classes, the professor first explained a concept, then displayed the related multiple choice question, and asked the students to discuss their answers. While most of the students participated in this peer instruction, some preferred to answer on their own. Students entered their answers once they felt ready. After 1-2 minutes, the professor announced ending the voting, and then ended it. The votes were immediately displayed as a bar chart, and the professor indicated the correct answer. Unless most of the students answered correctly, the professor briefly explained the justification for the correct answer. In a class session of 2.5 hours, 5-8 clicker questions were asked. During the 24 hours after the class, students logged in their reflections of their learning experience online.

\section{Questionnaire}

Validated constructs (for both questionnaires) were adopted from different relevant prior research work (Venkatesh et al., 2002; Agarwal \& Karahanna, 2000; Davis, 1989). The wording of items was changed to account for the context of the study. All items shown in the Appendix were measured using a 5-point scale with anchors for all of the questions from "Strongly disagree" to "Strongly agree".

\section{Result and Discussion}

\section{Affect and Intrinsic Motivation}

Affect and intrinsic motivation were measured by perceptions of fun, enjoyment, pleasantness, and interaction. In the online learning tool study, affect was reported to be primarily negative. Approximately half the students reported using the "learning tool" to be a nuisance, frustrating and stressful. This was attributed mostly to the fact that the course contained a large number of chapters to study. Arkklein (2003) reported that negative affect caused the students to avoid the use of the "learning tool".

Figure 2 presents the items of affect and intrinsic motivation for the technology mediated classroom using clickers and peer instruction. On all three items measuring affect and intrinsic motivation, approximately $65 \%$ of the students reported positively. Interestingly, the same percentage of students reported that participating in clicker and peer instruction bored them. This may be attributed to a misunderstanding of the question; while the question was about the use of clickers and peer instruction, the students may have responded about their perceptions of the course content. 


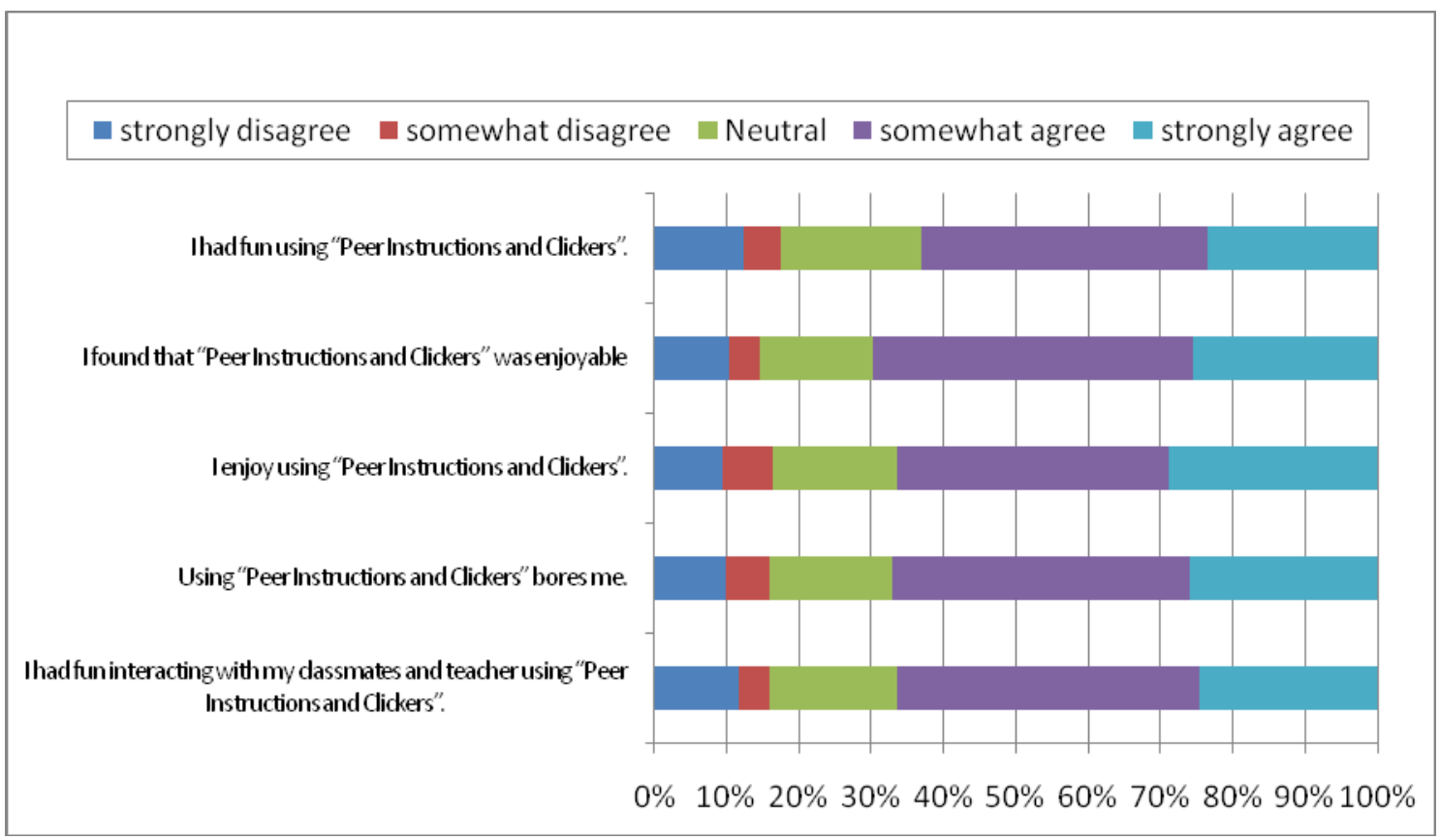

Figure 2. Student Feedback on Affect and Intrinsic Motivation.

The difference in affect and intrinsic motivation between the online course and clickers and peer insruction is from $50 \%$ to $65 \%$ respectively. In other words, students in the online course seemed to more negative by about $20 \%$. There could be many reasons for that:

- The online learning tool was an activity outside of the classroom while clickers were used in the classroom. Therefore, having more work to do outside the classroom most of the time might have led to negative affect and attitude with students

- The online learning tool is repetitive with no variation and that has been shown to be a negative design aspect of any information system. On the other hand, face-to-face interactivity of clicker use, although follows the same process, is never exactly the same because it allows for spontaneity and inquiry

- Motivation to use the online learning tool is purely individualistic. Namely, it was the percentage points gained doing the exercises. In other words, there is no peer or instructor support or collaboration to inspire or drive motivation. While when using clickers, it would take just one enthusiastic group member to motivate and engage the others. Moreover, the instructor can manage the motivation level by monitoring the interactivity and the classroom ambiance (so to speak) to decide when and how to intervene.

\section{Attitude and Extrinsic Motivation}

More than $80 \%$ of the students using the online learning tool perceived it as supporting their learning and thus were motivated to use it more regularly. The same percentage of students reported that they used it more seriously because it is part of the grading scheme. Both the intrinsic and extrinsic motivation played an important role in using the online learning tool.

Sixty percent of the students reported that the "learning tool" was helpful for understanding the course content, and that its advantages outweigh its disadvantages. Most students reported that the tool had little influence on their performance in other courses, and on feeling more productive by using it. This was due to the concept-focus of the topics in relation to the present course contrary to the other courses. On the other hand, $10 \%$ of the students did feel that the "learning tool" 
would help them in other courses, improved the quality of their interaction with other students and felt more productive using it.

As shown in Figure 3, approximately $67 \%$ of the students using clickers had positive attitude towards it, with two thirds believing that it is beneficial and a good idea. Around $62 \%$ of the students felt that using clickers is useful and has enhanced their learning of the content; however, significantly fewer students $(50 \%)$ felt that it has improved their performance in the course.

Although the difference in attitude between online learning tool and clicker and peer instruction is small, there seems to be a clear indication that there is a split in the opinions related to the association between clicker use and performance. This may be due to the course's quantitative nature. Business statistics is not an easy course and students are typically anxious about taking it.

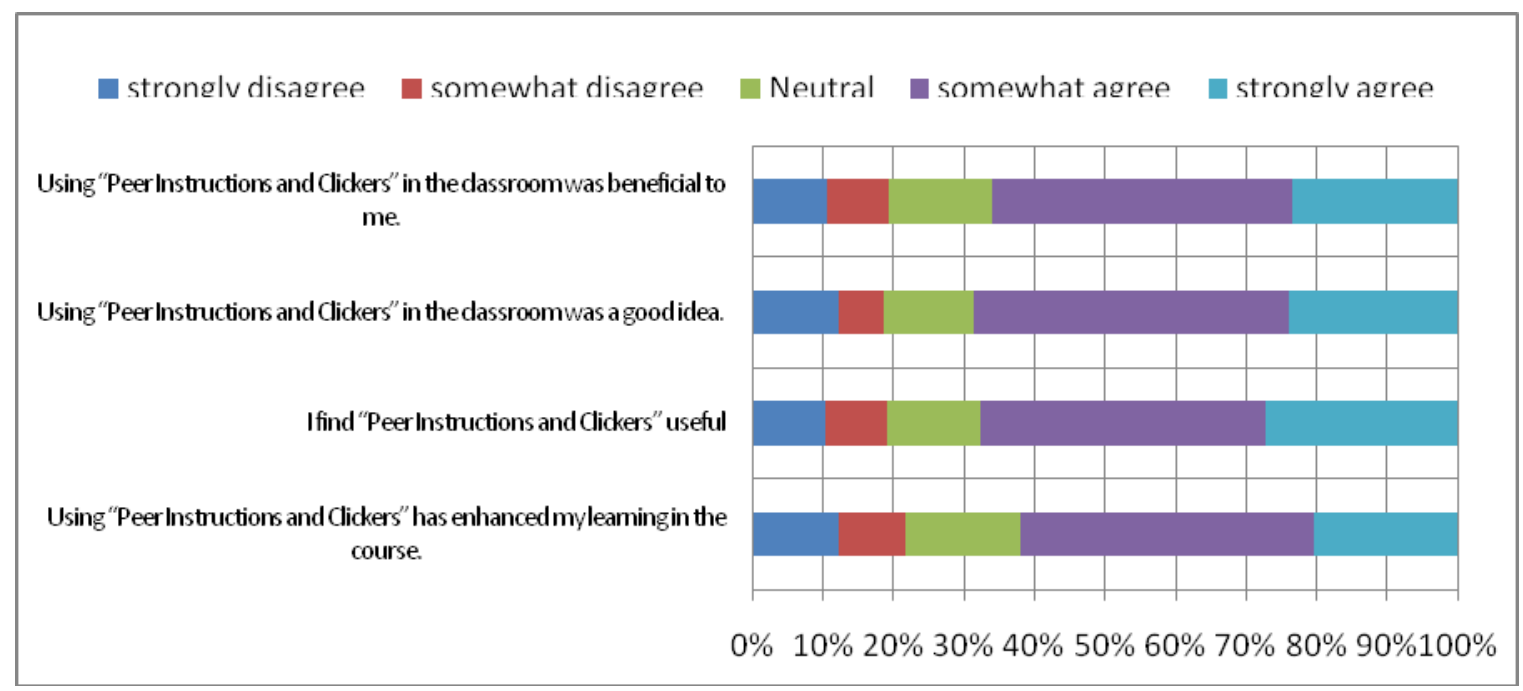

Figure 3. Student Feedback on Attitude and Extrinsic Motivation

\section{Exploratory Factor Analysis}

The exploratory factor analysis conducted in this study follows that of Saade et al. (2007). The maximum likelihood estimation method was used in the three factor analyses conducted. At first, four factors were selected with no appropriate 4-factor loading. Then three factors were attempted still with the same results. Finally, two factors were selected and the resulting items were retained and presented herein. In this study, we used orthogonal rotation which tends to maximize the loadings on one factor and minimize the loading on the remaining factors. The most commonly used rotation scheme for orthogonal factors is varimax, which attempts to minimize the number of variables that have high loadings on one factor.

\section{Factor Analysis}

First, we performed an initial factor analysis to observe the relationship among the four factors and their indicators. It was evident that two of the factors were loading well while the other two were not. The results indicated that external motivation and attitude were loading together while the loading of intrinsic motivation and affect were not clear. During subsequent factor analysis we rotated the matrix to improve our ability to interpret the loadings (to maximize the high loading of each observed variable on one factor and minimize the loading on the other factors). We also analyzed the factor eigenvalues since the eigenvalue (presented in Figure 4) for a given factor reflects the variance in all the variables, which is accounted for by that factor (Nagpaul, 1999). The factors with eigenvalues greater than 1.0 contain acceptable variance among the observed 
items while those with eigenvalues significantly less than 1.0 need to be dropped from the factor solution.

Analysis of eigenvalues was done by considering a scree-plot, (Figure 5) which presents the number of factors that is possible to extract from the pool of items.

\section{Retained Solution}

Table 1 presents the 4 (a) and 2 (b) factor loadings for the clicker case (please refer to the appendix for listing of variables corresponding to the codes). Factor loadings above 0.5 on respective items for online learning tool and clickers are presented in Table 1b. Table 1a shows that in the case of clickers, the four variables selected in this study are not discriminated and load only on two factors (table 1b). Items with high values are bolded to contrast the loading on their respective factor. Items that belong together have relatively higher loadings on the same factor.

Table 1. Factor loadings on respective items

a. Clickers and peer instruction -4 factor loading)

\begin{tabular}{|c|c|c|c|c|}
\hline Code & \multicolumn{1}{|c|}{ Factor1 } & Factor2 & Factor3 & Factor4 \\
\hline PU1 & $\mathbf{0 . 7 6 2}$ & -0.290 & -0.244 & 0.100 \\
\hline PU2 & $\mathbf{0 . 8 8 0}$ & -0.273 & -0.262 & 0.031 \\
\hline PU3 & $\mathbf{0 . 7 5 7}$ & -0.286 & -0.294 & 0.283 \\
\hline ATT1 & $\mathbf{0 . 6 6 1}$ & -0.343 & -0.338 & 0.576 \\
\hline ATT2 & $\mathbf{0 . 7 0 4}$ & -0.356 & -0.401 & 0.219 \\
\hline ENJ1 & 0.351 & $-\mathbf{0 . 8 7 3}$ & -0.300 & 0.157 \\
\hline ENJ2 & 0.416 & -0.592 & -0.558 & 0.102 \\
\hline ENJ3 & 0.399 & -0.594 & -0.510 & 0.161 \\
\hline AFF1 & 0.312 & -0.445 & -0.591 & 0.072 \\
\hline AFF2 & -0.137 & 0.121 & 0.427 & -0.075 \\
\hline AFF3 & 0.488 & -0.489 & -0.498 & 0.276 \\
\hline
\end{tabular}

b. Clickers and peer instruction -2 factor loading)

\begin{tabular}{|c|c|c|c|}
\hline Code & Factor1 & Factor2 & OLT - Loadings \\
\hline PU1 & $\boldsymbol{0 . 7 4 5}$ & 0.377 & -0.556 \\
\hline PU2 & $\mathbf{0 . 8 1 5}$ & 0.383 & \\
\hline PU3 & $\boldsymbol{0 . 8 4 3}$ & 0.386 & \\
\hline ATT1 & $\boldsymbol{0 . 7 6 1}$ & 0.514 & 0.666 \\
\hline ATT2 & $\mathbf{0 . 7 6 0}$ & 0.516 & 0.672 \\
\hline ENJ1 & 0.385 & $\mathbf{0 . 8 3 6}$ & -0.574 \\
\hline ENJ2 & 0.449 & $\mathbf{0 . 7 9 5}$ & \\
\hline ENJ3 & 0.416 & $\mathbf{0 . 8 0 4}$ & \\
\hline AFF1 & 0.344 & $\mathbf{0 . 6 9 6}$ & -0.877 \\
\hline AFF3 & 0.550 & $\mathbf{0 . 6 9 8}$ & -0.650 \\
\hline
\end{tabular}

(See Saadé et al., 2007 for details to factor loadings for OLT)

Table 1 shows that the affect and attitude in the online learning tool are represented more than the motivational variables. The opposite seems to be true for the clickers since the four original factors actually load on two factors and most interestingly, the motivational (intrinsic and extrinsic) constructs. Attitude in clickers loaded with extrinsic motivation while affect loaded with intrinsic 
motivation. Moreover, the loading in the clicker case are much higher than those in the online learning tool case.

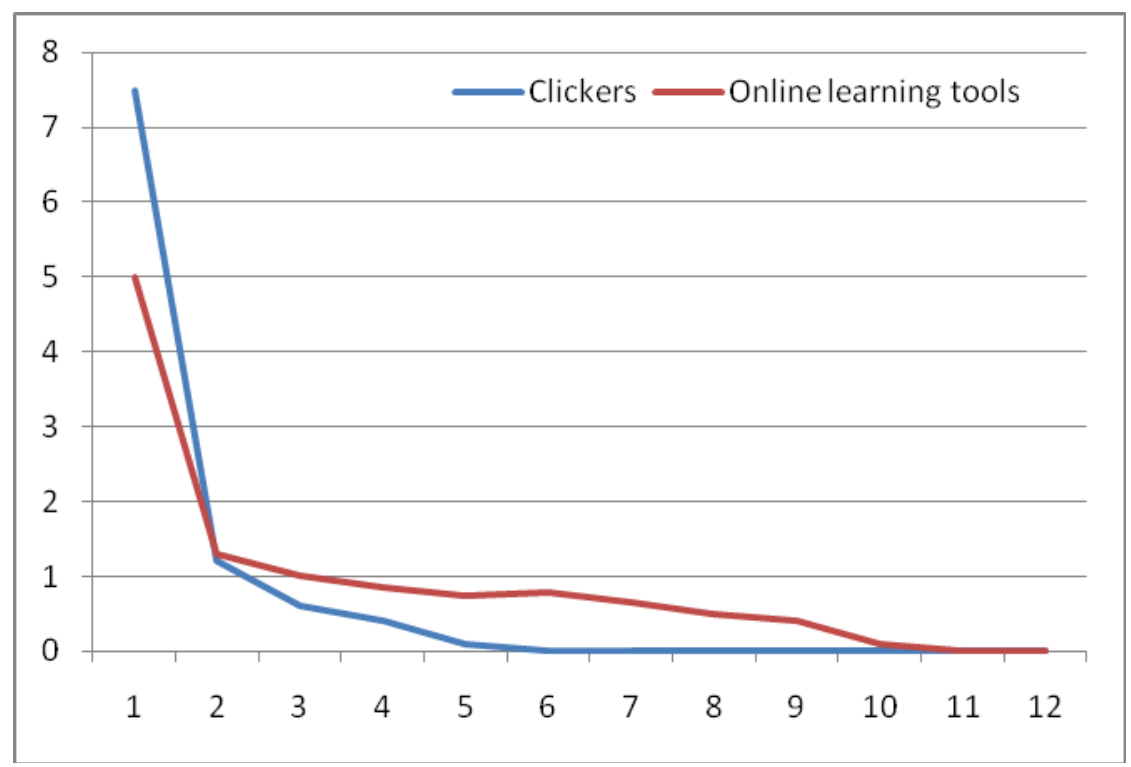

Figure 4. Eigenvalues for factors reflecting variance in items (Left: online learning tool; Right: clickers)

\section{Limitation and Conclusion}

The study of dimensions that influence technology mediated learning under different contexts is scarce. In this study, we identified four constructs and associated items obtained from different theories and compared the factor structures obtained in the context of clicker and peer instructions usage in a face-to-face classroom and online learning tool used outside the classroom. We acknowledge that implications of our findings are only confined to the limits at which we interpret the results, and that these limitations must be acknowledged.

The two studies have differences that have an impact on the extent to which they can be compared. These differences are as follows:

- From the participants' perspective, differences in the sample of learners (sample size, and demographic controls) are not exactly the same even if they are similar

- The nature of the courses involved is different; the online learning tool is used in an introductory management of information systems course while clickers were used in an introductory business statistics course.

- The requirements to use the technology in each course is different; to use the online learning tool, students were required to learn many chapters and additional topics outside of the classroom, while the clicker activity occurred as part of the classroom time.

- The questionnaire is not free from subjectivity. The respondents' self-report measures used are not necessarily direct indicators of improved learning outcomes. Additionally, the loading of the factors in disagreement with the theory they originated from further implies to the possible problems with the items fitting within the context. In other words, although a proper validation process of the instrument was followed, the fact that the questions were collected from other research may not necessarily be precise and appropriate in the context of this study. 
- Conclusions drawn are based on a specific technology usage as well as the process surrounding its use and thus cannot be generalized to all learning technologies.

Intrinsic and extrinsic motivation seems to be the dominant emotions in clicker use where students see the benefits of clickers and peer instruction while enjoying the process.

\section{References}

Agarwal, R., \& Karahanna, E. (2000). Time flies when you're having fun: Cognitive absorption and beliefs about information technology usage. MIS Quarterly, 24(4), 665-694.

Ajzen, I. (1985). From intentions to actions: A theory of planned behavior. In J. Kuhl \& J. Beckman (Eds.), Action-control: From cognition to behavior (pp11-39). Heidelberg: Springer.

Arkkelin, D. (2003). Putting Prometheus' feet to the fire: Student evaluations of Prometheus in relation to their attitudes towards and experience with computers, computer self-Efficacy and preferred learning style. Retrieved February 22, 2011, from http://faculty.valpo.edu/darkkeli/papers/syllabus03.htm

Bozionelos, G., \& Bennett, P. (1999). The theory of planned behavior as predictor of exercise. Journal of Health Psychology, 4(4).

Campbell, J. \& Mayer, R. E. (2009). Questioning as an instructional method: Does it affect learning from lectures? Applied Cognitive Psychology, 23, 747-759.

Daley, B. J., Watkins, K., Williams, S. W., Courtenay, B., Davis, M., \& Dymock, D. (2001). Exploring learning in a technology-enhanced environment. Educational Technology \&Society, 4(3), 126-138.

Dalgarno, B. (2001). Interpretation of constructivism and consequences for computer assisted learning. British Journal of Educational Technology, 32(2), 183-194.

Davis, F. D., Bagozzi, R. P., \& Warshaw, P. R. (1989). User acceptance of computer technology: A comparison of two theoretical models. Management Science, 35(8), 982-1003.

Davis, F. D. (1989). Perceived usefulness, perceived ease of use, and user acceptance of information technology. MIS Quarterly, 13(3), 319-339.

Deci, E. L., \& Ryan, R. M. (1985). Intrinsic motivation and self-determination in human behavior. New York: Plenum Publishing Co.

Fishbein, M., \& Ajzen, I. (1975). Belief, attitude, intention, and behavior: An introduction to theory and research. Reading, MA: Addison- Wesley. 89-114.

Gupta, S., \& Bostrom, R. P. (2009). Technology-mediated learning: A comprehensive theoretical model. Journal of the Association for Information Systems, 10(9), 686-714.

Mayer, R. E. (1989). Models for understanding. Review of Educational Research, 59, 43-64.

Mayer, R. E., Stull, A., DeLeeuw, K., Almeroth, K., Bimber, B., Chun, D., Bulger, M., Campbell, J., Knight, A. \& Zhang, H. (2009). Clickers in college classrooms: Fostering learning with questioning methods in large lecture classes. Contemporary Educational Psychology, 34, 51-57.

Patterson, B., Kilpatrick, J., \& Woebkenberg, E. (2010). Evidence for teaching practice: the impact of clickers in a large classroom environment. Nurse Education Today, 30(7), 603-607.

Poole, B. J., \& Lorrie, J. (2003). Education online: Tools for online learning. Education for an information age, teaching in the computerized classroom (4th ed.).

Saadé, G. R. (2003). Web-based educational information system for enhanced learning, (EISEL): Student assessment. Journal of Information Technology Education, 2, 267-277. Retrieved from http://www.jite.org/documents/Vol2/v2p267-277-26.pdf 
Saadé, G. R. (2007). Dimensions of perceived usefulness: Towards enhanced assessment. Decision Sciences Journal of Innovative Education, 5(2), 289-310.

Saadé, G. R., \& Bahli, B. (2005). The impact of cognitive absorption on perceived usefulness and perceived ease of use in online learning: An extension of the technology acceptance model. Information \& Management, 42, 317-327.

Saadé, G. R., \& Galloway, I. (2005), Understanding the acceptance of multimedia applications for learning. Issues in Informing Science and Information Technology, 2, 287-296. Retrieved from http://2005papers.iisit.org/I23f15Saad.pdf

Saadé, G. R., \& Huang, Q. (2009). Meaningful learning in discussion forums: Towards discourse analysis. Issues in Informing Science and Information Technology, 6, 87-99. Retrieved from http://iisit.org/Vol6/IISITv6p087-099Saade675.pdf

Saadé, G. R., Nebebe, F., \& Mak, T. (2010). Knowledge management systems development: Theory and practice. Interdisciplinary Journal of Information, Knowledge and Management, 6, 35-72. Retrieved from http://www.ijikm.org/Volume6/IJIKMv6p035-072Saade472.pdf

Saadé, G. R., Nebebe, F., \& Tan, W. (2007). Viability of "Technology Acceptance Model” in multimedia learning environments: A comparative study. Interdisciplinary Journal of Knowledge and Learning Objects, 3, 175-184. Retrieved from http://www.ijello.org/Volume3/IJKLOv3p175-184Saade393.pdf

Sprague, E. W., \& Dahl, D. W. (2009). Learning to click: An evaluation of the personal response system clicker technology in introductory marketing courses. Journal of Marketing Education, 32(1), 93-103.

Stagg, A. \& Lane, M. (2010). using clickers to support information literacy skills development and instruction in first-year business students. Journal of Information Technology Education, 9, 197-215. Retrieved from http://www.jite.org/documents/Vol9/JITEv9p197-215Stagg800.pdf

Sunal, W. D., Sunal, S. C., Odell, R. M. \& Sundberg, A. C. (2003). Research-supported best practices for developing online learning. The Journal of Interactive Online Learning, 2(1), 1-40.

Triandis, H. C. (1980). Values, attitudes, and interpersonal behavior. In Nebraska symposium on motivation, 1979: Beliefs, attitudes, and values, University of Nebraska Press, Lincoln, NE, 195-259.

Vallerand, R. J. (1997). Toward a hierarchical model of intrinsic and extrinsic motivation. Advances in Experimental Social Psychology, 29, 271-374.

Valenta, A., Therriault, D., Dieter, M., \& Mrtek, R. (2001). Identifying student attitudes and learning styles in distance education. The Journal of Asynchronous Learning Networks, 5 (2).

Venkatesh, V. (1999). Creation of favorable user perceptions: Exploring the role of intrinsic motivation. MIS Quarterly, 23, 239-260.

Venkatesh, V., \& Davis, F. D. (2000). A theoretical extension of the technology acceptance model: Four longitudinal field studies. Management Science, 46, 186-204.

Venkatesh, V., Speier, C., \& Morris, M. G. (2002). User acceptance enablers in individual decision making about technology: Toward an integrated model. Decision Sciences, 33(2), 297-316.

Wlodkowski, R. J. (1999). Enhancing adult motivation to learn, revised edition, a comprehensive guide for teaching all adults. San Francisco, CA: Jossey-Bass. 


\section{Appendix: Question items in the questionnaire.}

\begin{tabular}{|l|c|l|}
\hline Construct & Code & Question \\
\hline Affect & AFF1 & I found that "Peer Instructions and Clickers" was enjoyable. \\
\hline & AFF2 & The process of using "Peer Instructions and Clickers" was pleasant. \\
\hline & AFF3 & I had fun using "Peer Instructions and Clickers". \\
\hline Attitude & ATT1 & $\begin{array}{l}\text { Using "Peer Instructions and Clickers" in the classroom was a good } \\
\text { idea. }\end{array}$ \\
\hline Intrinsic Motivation & IM1 & $\begin{array}{l}\text { I had fun interacting with my classmates and teaching using "Peer In- } \\
\text { structions and Clickers". }\end{array}$ \\
\hline & IM2 & Using "Peer Instructions and Clickers" bores me. \\
\hline & IM3 & I enjoy using "Peer Instructions and Clickers". \\
\hline Extrinsic Motivation & EM1 & $\begin{array}{l}\text { Using "Peer Instructions and Clickers" has enhanced my learning in } \\
\text { the course. }\end{array}$ \\
\hline & EM2 & I find "Peer Instructions and Clickers" useful. \\
\hline
\end{tabular}

\section{Biographies}

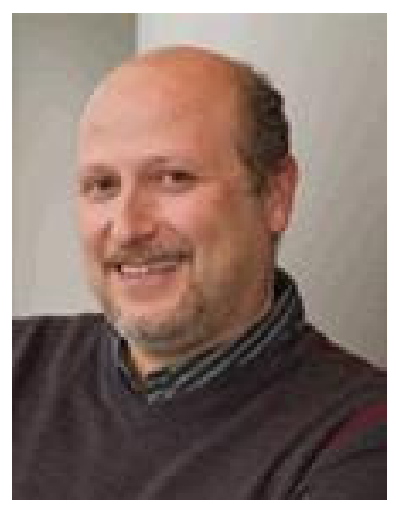

Dr. Raafat George Saade has been teaching in the faculty since 1998. He obtained his Ph.D. in 1995 (Concordia University) after which he received the Canadian National Research Council postdoctoral fellowship, which he completed at McGill University in Montreal. Dr. Saade has published in journals such as Information \& Management, Decision Sciences, and Expert Systems with Applications. His research interests include the development and assessment of information systems, and the supply chain of digital information products.

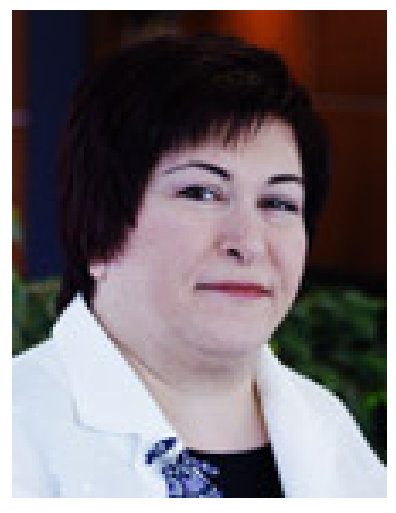

With the Faculty since 1984, Dr. Büyükkurt obtained her BA in Accounting and Finance from Bogazici University (Turkey), her MBA (Major in Decision Sciences) from Indiana University and her PhD in Business with a major in Decision Sciences and minors in MIS and Statistics from Indiana University. She was a visiting assistant professor at Washington State University (1983-84), visiting scholar at Indiana University (1991-1992) and a visiting associate professor at Koç University, Turkey, (1994-1996).

She teaches Information Systems Analysis and Design, and Decision Making Under Uncertainty. Her research focuses on Information system development including end-user computing, quantification and measurement of uncertainty in information presentation and decision making, and adoption of recent technologies such as data mining. 


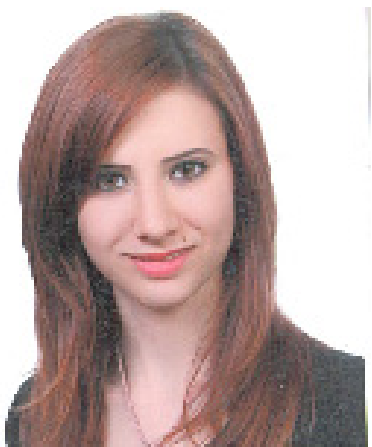

Cynthia Alkhori is a graduate from Finance, Bachelors of Business Administration, Higher institute of business Administration (HIBA), Damascus, Syria. Currently she is majoring in Human Resource Management, John Molson School of Business, Montreal, Canada. She has been working for the past year on research related to technology mediated learning in large classes. 